\title{
A Qualitative Inquiry Into the Challenges of Medical Education for Retention of General Practitioners in Rural and Underserved Areas of Iran
}

\author{
Sajad Delavari', Mohammad Arab', Arash Rashidian', Saharnaz Nedjat', Rahmatollah Gholipour Souteh ${ }^{3}$ \\ ${ }^{1}$ Department of Health Management and Economics, School of Public Health, Tehran University of Medical Sciences, Tehran; ${ }^{2}$ Department of \\ Epidemiology and Biostatistics, School of Public Health, Knowledge Utilization Research Center, Tehran University of Medical Sciences, Tehran; \\ ${ }^{3}$ Department of Public Policy, Faculty of Management, University of Tehran, Tehran, Iran
}

Objectives: General practitioners (GPs) retention in rural and underserved areas highly effects on accessibility of healthcare facilities across the country. Education seems to be a critical factor that affects GPs retention. Thus, the present study aimed at inquiry into medical education challenges that limit their retention in rural and underserved areas.

Methods: A qualitative approach was applied for the aim of this study. Data were gathered via 28 semi-structured interviews with experts at different levels of Iran's health system as well as GPs who retained and refused to retain working in rural settings. Interviews mainly were performed face-to-face and in some cases via telephone during 2015 and then coded and analyzed using content analysis approach.

Results: Iran's medical education is faced with several challenges that were categorized in four main themes including student selection, medical students' perception about their field of study, education setting and approach, curriculum of medical education. According to experts this challenges could results in making GP graduates disinterested for practicing in rural and underserved areas. Conclusions: Challenges that were found could have negative effects on retention. Modification in student's perception about rural practice could be done via changing education setting and approach and curriculum. These modifications could improve GPs retention in rural and underserved areas.

Key words: Medical education, General practitioners, Rural health

Received: June 20, 2016 Accepted: October 17, 2016

Corresponding author: Mohammad Arab, PhD

Poursina Ave., Tehran 1417613151, Iran

Tel/Fax: +98-2188989129

E-mail: arabmoha@tums.ac.ir

This is an Open Access article distributed under the terms of the Creative Commons Attribution Non-Commercial License (http://creativecommons.org/licenses/bync/4.0/) which permits unrestricted non-commercial use, distribution, and reproduction in any medium, provided the original work is properly cited.

\section{INTRODUCTION}

Achieving Universal Health Coverage, which is the aim of countries' health system, requires making healthcare accessible for all of its citizens. Access to health is a right for all people regardless of their religion, ethnicity, and living place. This issue is declared in several documents, the Constitution of World Health Organization (WHO), and Article 29 of the Constitution of Islamic Republic of Iran. WHO in "Health for All" policy emphasizes on achievement of all people to the highest attainable level of health. 
Despite all of these assertions, in many countries habitants of rural and underserved areas have some barriers in accessing healthcare. For example in China, rural women do not utilize healthcare facilities equitably with urban women $[1,2]$. This is the same for Ghanaian women $[3,4]$. This is not just related to developing countries. In the US, rural population is more likely to be dissatisfied with the healthcare provided compared with urban population [5]. Also, rural population of New York State has worse health behavior and do not have a regular medical care provider [6]. By proportion, rural settings of Canada have fewer healthcare providers than urban locations [7]. This is called inverse care law that states those who need more health care, have less access that could be seen in different contexts [8-10].

General practitioners (GPs) are one of the main providers of healthcare. In fact they are the gateway of health system in many countries [11,12]. In this regard, Iranian Family Physician Plan and rationing system heavily depends on GPs $[12,13]$. Thus, they should be accessible in every place for all citizens which can guide them in the health system.

But, in rural and underserved areas lack of GPs hinder accessing peoples to healthcare. In fact GPs are not motivated to work in rural and underserved areas. In a study which is done in China, only one third of medical students have positive attitude toward working in rural and underserved areas [14]. As well, less than $18 \%$ of Japanese medical students are positively motivated for rural practice and more than $25 \%$ declared they will avoid rural practice [15]. Also in School of Medicine of University of Miami Miller, more than $36 \%$ of medical students which volunteered at a rural health fair have not planned to practice as a primary care provider [16].

It seems that medical education is a key factor in motivating GPs for working in rural and underserved areas [17]. Medical education policies including student selection, curriculum, education place, and etc. could have significant impact on their motivation. Regarding to pivotal role of education in retention, medical education in Iran should be analyzed and accordingly strategies set for their retention in rural areas.

Accordingly education is one of the most important issues that could affect GPs retention in rural and underserved areas. Regarding to importance of the issue, the present research aimed at exploring challenges in medical education that makes GPs disinterested for working in rural and underserved areas. This issue is very important and the results of this research could help policy makers and educational planners for addressing GPs retention in rural areas with intervention in their education process.

\section{METHODS}

Qualitative design was applied for the purpose of the study and data were collected via interviews. Prior to starting qualitative study, reviewing the literature was done and accordingly topic guide for interviews was extracted for interviews. Topic guide mainly focused on challenges of medical education and educational strategies for GPs retention in rural and underserved areas. Questions of topic guide were about challenges and strategies in student selection, education place, curriculum, instructors and faculty members, and necessary skill for rural practice. Although, during interviews and according to participants responses some modification in topic guide were made. Based on topic guide and its modifications, deep and semi-structured interviews were conducted from March 2015 to June 2015 with different types of participants.

Participants were divided in three main categories including faculty members and academic key informants, executive key informant, and GPs who retained at least five years in rural and underserved areas as well as GPs who avoid continuing rural practice. Participants were selected using purposive and snowball sampling with maximum variation approach. We tried to cover all areas and we select sample from all over the country at micro and macro level of the Iran's health system.

Interviews were performed until reaching to data saturation. Finally, 6 academic informants (PA1-PA6), 8 executive key informants at micro and macro level of Ministry of Health and Medical Education (PE1-PE8), and 8 GPs who retained (PPR1PPR8) as well as 6 GPs who avoid practicing in rural settings (PPA1-PPA6) were selected for interview. Although, most of participants in three categories (24 from 28 participants) had studied medicine and were well informed about medical education and thus the results would be reliable.

From all 28 interviews, 21 were performed face-to-face. Since GPs mainly works in remote areas and hardship in faceto-face interview, seven GPs were interviewed via telephone. The interview time varied from 24 minutes to 60 minutes and the average time was 39 minutes. This average for face-to-face interviews was 42 minutes and 35 minutes for telephone ones. Except one interview (in the case of telephone interview which the participant did not allow recording), all others were recorded and transcribed verbatim and in one case interview- 
er noted during interview. Coding was checked by two experts in qualitative research and it was confirmed. Data were analyzed using content analysis approach. In this way, texts were coded and issues and subthemes were extracted. The main themes were created via interpretation of codes and issues.

Several ethical issues were considered in interviews with participants. All participants approved a written or recorded informed consent before beginning the interview. They were informed about recording or noting of interviews. Also they were consented to attend in the study and free to express their opinions about the subject. Interviewees were ensured the confidentiality of recorded and noted interviews and their names and positions. As well, the study protocol complies with the ethical guidelines of the 1975 Declaration of Helsinki and approved by ethics committee of Tehran University of Medical Sciences (code: IR.TUMS.REC.1395.2648).

\section{RESULTS}

After analyzing and data interpretation, we found four main themes including student selection, medical students' perception about their field of study, education setting and approach, curriculum of medical education. Each of these main themes encompasses several subthemes and accordingly each subtheme encompasses several issues. The thematic framework of the findings is presented in Table 1. According to Table 1, challenges of medical education for retention in rural and underserved areas of Iran are as follow:

\section{Student Selection}

Several challenges in student selection cause selecting improper students who are not much likely to work in rural settings. One challenge is nativity of student which has debate among interviewed participants. One idea says rural student are more likely to go back to their village. Another one says rural population accept incomer GPs more than aborigine ones. A GP said:

My wife and I were from a big city which worked in rural areas of Kurdistan [a deprived province in west of lan]... People honor and accept us better than other GPs which were from Kurdistan. They were so hospitable about us...(PPA4).

Gender of accepted medical student is another challenge. Now in Iran medical education system, women are more than half of medical students which are not much eager to work in rural settings and thus they cause heavy cost for health sys- tem. Another issue about women GPs in rural settings is their security which is stated by one of executive experts:

We have problems with security of women GPs in rural areas which pose us heavy costs (PE4).

Another issue about student selection is that most of medical students have urban backgrounds which are not able to communicate with rural population. As well, the entrance exam and selection process is in a way that rich students and those in high socioeconomic levels are mainly selected for medicine. Medicine is one of the most popular fields in Iran that wealthy families spent much money for their sons or daughters to be accepted for medicine. So, most of students are from wealthy families. An executive expert who has studied medicine said:

....medical students are selected from rich families. They haven't experienced any trouble in their life...villages are deprived and have many problems in facilities, transportation, .... welfare-experienced GPs couldn't retain with difficulties... (PE6).

\section{Medical Students' Perception About Their Field of Study}

Medical students are not well oriented about their future working conditions. They are educated more about specialized subjects and basic sciences. In fact they are looking for specialized degrees of medicine. As well, low perceived income of GPs motivates them for higher degrees. In this case even when they are working in rural settings, they are thinking of continuing education in higher degrees and try to study hard instead of working for rural population. A GP said:

All of my classmates who were attended in specialized fields have better situation than me (PPA2).

Also, specialized entrance exam focuses on complicated diseases instead of prevalent diseases in rural area. Thus, medical students have a misconception about their future working condition and ambiguity about their role in health system. They are educated in a way that they think they should work in urban settings while health system expect them working in rural settings. A GP states that:

We aren't oriented about our role in health system ... In student time we weren't exposed to rural settings and now they want me to work in rural settings ... the system ask us studying specialized courses ... I think GP is an incomplete mission (PPA3).

\section{Education Setting and Approach}

Education setting and approach could be as important as 
Table 1. Thematic framework of challenges in medical education for rural practice

\begin{tabular}{|c|c|c|}
\hline Main themes & Subthemes & Issues \\
\hline \multirow[t]{4}{*}{$\begin{array}{l}\text { Student } \\
\text { selection }\end{array}$} & Nativity & $\begin{array}{l}\text { Rural student are more likely to go back to their village } \\
\text { Rural population accept incomer GPs more than aborigine ones }\end{array}$ \\
\hline & Gender & $\begin{array}{l}\text { High cost of women physician in rural areas } \\
\text { Lack of women's tendency for working in rural settings } \\
\text { Women's dependency on their husbands }\end{array}$ \\
\hline & Residency & $\begin{array}{l}\text { Unfamiliarity of urban students with rural settings } \\
\text { Inability of urban student for communication with rural population }\end{array}$ \\
\hline & $\begin{array}{l}\text { Socioeconomic status of } \\
\text { selected students }\end{array}$ & $\begin{array}{l}\text { Medical Students are mainly selected from wealthy families } \\
\text { Rural settings have no welfare motivation for welfare-experienced GPs }\end{array}$ \\
\hline \multirow[t]{2}{*}{$\begin{array}{l}\text { Medical students' } \\
\text { perception about } \\
\text { their field of study }\end{array}$} & $\begin{array}{l}\text { Medical students } \\
\text { expectations }\end{array}$ & $\begin{array}{l}\text { Misconception about working conditions of GPs in the future } \\
\text { Lack of exposure with rural patients during education } \\
\text { Misconception about working in rural and underserved areas } \\
\text { Tendency to welfare among medical students }\end{array}$ \\
\hline & $\begin{array}{l}\text { Tendency toward attending } \\
\text { in specialization courses }\end{array}$ & $\begin{array}{l}\text { Much income difference between specialized physicians and GPs } \\
\text { Ambiguity about GPs role in health system } \\
\text { GPs pay attention to higher degrees entrance exam instead of working and communicating in rural areas } \\
\text { Higher degrees entrance exam focuses on complicated diseases instead of rural and health courses }\end{array}$ \\
\hline \multirow[t]{3}{*}{$\begin{array}{l}\text { Education setting } \\
\text { and approach }\end{array}$} & $\begin{array}{l}\text { Instructors and faculty } \\
\text { members }\end{array}$ & $\begin{array}{l}\text { Most instructors does not have rural working experience } \\
\text { Lack of emphasis on ethical issues by instructors }\end{array}$ \\
\hline & Education place & $\begin{array}{l}\text { Education in big cities } \\
\text { Education in cities with different culture }\end{array}$ \\
\hline & $\begin{array}{l}\text { Hospital oriented medical } \\
\text { education }\end{array}$ & $\begin{array}{l}\text { Medical students should handle patients in specialized hospitals } \\
\text { Medical students face with complicated patients in hospitals } \\
\text { Medical students work on second and third hand patients, not outpatient in their apprenticeship courses }\end{array}$ \\
\hline \multirow[t]{5}{*}{$\begin{array}{l}\text { Curriculum of medical } \\
\text { education }\end{array}$} & $\begin{array}{l}\text { Skills needed for rural } \\
\text { practice }\end{array}$ & $\begin{array}{l}\text { Unfamiliarity of graduated GPs with Family Physician Plan } \\
\text { Lack of patient management skills education } \\
\text { Rural apprenticeship does not prepare GPs for rural practice } \\
\text { Medical students are not faced with rural patients and not aware of their needs }\end{array}$ \\
\hline & $\begin{array}{l}\text { Negligence of health } \\
\text { related courses }\end{array}$ & $\begin{array}{l}\text { GPs' health role is neglected in education while in rural settings it is more important than their } \\
\text { therapeutic role } \\
\text { Lack of education about common diseases in rural areas } \\
\text { Lack of education about health indices and indicators }\end{array}$ \\
\hline & $\begin{array}{l}\text { Management and } \\
\text { leadership skills }\end{array}$ & $\begin{array}{l}\text { GPs in rural settings are the manager of health team } \\
\text { GPs need meeting skills } \\
\text { GPs are health coordinator and need coordination skills } \\
\text { GPs need resource management skills } \\
\text { GPs need advocacy skills }\end{array}$ \\
\hline & Communication skills & $\begin{array}{l}\text { Patient trust in physicians needs good communication skills } \\
\text { Skills for communication with rural settings is needed } \\
\text { Lack of education about types of patient in rural areas } \\
\text { Lack of education about communication with rural people and patients }\end{array}$ \\
\hline & Medical ethics & $\begin{array}{l}\text { Lack of sense of belonging and commitment toward providing services to rural population } \\
\text { Low morale in medical students } \\
\text { Negligence of values of working for deprived population } \\
\text { Not serious education of medical ethics }\end{array}$ \\
\hline
\end{tabular}

GP, general practitioner.

curriculum. It refers to factors that education is delivered via them including education approach, place of education, and instructors. These factors could have a significant effect on GPs interest for working in rural or urban settings.

Nearly in all medical schools of Iran, medical education is hospital oriented. Most of practical courses are presented in hospitals and students are not getting familiar with rural set- tings and health issues. This approach could have a significant effect on medical students' perception about their future working condition. A GP said:

We educated here [hospital]...we weren't prepared for rural settings (PPA5).

Another expert said:

Most of services in hospitals are delivered by medical students 
... as human resource ... we need them in hospital for service delivery (PA2).

Instructors are one of the important factors in education that could guide GPs ideas and thoughts. Instructors who experienced working in rural settings and try to motivate their students for rural practice are key factors. Students patterned form their instructors and if they stress on self-sacrifices, the spirit of working for deprived people, and medical ethics, students will be affected.

Education place is another factor that could affect tendency for rural practice. Education city and its culture could determine students' perception about future working place. Education in cities which have different cultural background with rural settings could hinder working in rural settings. An expert said:

When a rural student comes to Tehran [the biggest and capital city of Iran with population over 10 million] from a small city or village, and see there will be adopted to its cultural situation over seven years of medical education, we shouldn't expect him/ her to come back to his/her own village... we make him/her familiar with a different culture that he/she thinks it is better (PA1).

\section{Curriculum of Medical Education}

There are some challenges regarding to curriculum of medical education; i.e., some courses are needed for preparing GPs for rural practice. In this study we found that focusing on skills needed for rural practice, health related courses, management and leadership, communication, and medical ethics could make GPs ready to an accept practicing in rural settings.

Family Physician Plan is implemented in villages and cities below 20 thousands population. GPs are the gateway and most of GPs in rural settings are collaborating in this plan. GPs unfamiliarity with Family Physician Plan causes some problem in rural practice. An expert stated:

At the first day of a GP practice in a village, he had a patient and he wanted to fill and sign the referral sheet for the patient. He didn't know how to handle the sheet...the patient found this and this resulted in bad reputation of the GP...They [rural population] think that he [the GP] doesn't have enough skill of treating... he escaped after three weeks... (PE2).

Patient management is also critical skill for rural practice. A GP requires treating patient independently in rural settings. Rural apprenticeship is a good situation for GP students' familiarity with skills needed for rural practice. A GP stated:

We didn't know how to treat cold even when we were intern [last year of medical education]. What we were thought were specialized and details about cold virus ... we lack patient management skills... (PPA3).

Another point is that GPs in rural settings work more on health issues instead of treatment and cure. They are the head of health system and they need to have perception about health subjects such as epidemiology, social determinants of health, health houses and their functions, etc. Nevertheless, as GPs stated, their education is different from what is needed in rural settings. They learn mainly about treatment of complicated cases in specialized hospitals. A GP said:

...many complicated issues instead of humble health issues that we need them more in rural settings...(PPR1).

Another needed skill for GPs in rural areas is management and leadership. They are the manager of health team and health coordinator in the region. Thus, they need skills such as meeting, coordination, advocacy and negotiation, and resource management skills. A GP stated:

What we are here is more manager and coordinator than $G P$... a good GP who can retain in rural settings should be a good manager (PPR8).

\section{DISCUSSION}

GPs are the key healthcare provider in rural and underserved areas of Iran and their retention is a crucial issue which is rarely addressed in research projects. Education is a factor that could affect GPs retention in rural areas and accordingly this qualitative research was done to find educational challenges that limit GPs rural intention to work. According to the results four main challenges were identified in GPs' education including student selection, medical students' perception about their field of study, education setting and approach, and curriculum of medical education.

It was found that dominance of non-native, women, urban, and welfare-experienced students are challenges in student selection that make graduates less intended for working in rural and underserved areas. Student selection criteria as a strategy for GPs retention in rural and underserved areas was highly debated in literature that could forecast retention. Several studies found that women are less positive about rural practice $[14,18]$. Rural origin also could be a good predictor for rural practice of GPs [19-21]. Parental education level [22], occupation of father [21] and cultural background [23], as socioeconomic factors, are significant factors on GPs retention. Relations between personality and retention in rural settings 
also confirmed $[18,23]$. Even GPs' spouse could determine rural practice [24] that could be addressed. On the contrary, Dossajee et al. [25] found that rural background, marital status, religion, and gender of Kenya medical students did not affect urban or rural practice. Also, Amiresmaili et al. [26] found there is no definite relation between demographic factors and retention in rural family physician plan. Thus student selection as a factor that affects retention in rural settings should be considered and its challenges should be minimized; although, somehow is addressed in entrance quotas for medical students in Iran. Maybe this issue needs more well designed studies for Iranian GPs to evaluate the effect of demographic factors on GPs retention.

Another challenge was related to students' perception about their future working condition. Most of students look for specialized courses in medicine and they would not stay GP. They do not consider rural practice after graduation in many cases. In fact Students' perception about their personal career development is a factor that affects retention in rural area [14,27]. Personal and professional expectations also proved as a factor affecting on retention [23]. On the other hand GPs are not exposed to rural settings and they do not think about rural practice in future [19]. Even short-stay in rural settings could be effective for retention [28]. Whereas, good and positive rural training experiences increase GPs' interest for rural practice and retention [29]. Accordingly it seems necessary that some modification in education is needed to guide students' perception toward rural practice after graduation.

Curriculum of medical education in Iran is a factor that does not properly make GPs ready for rural practice. Stearns and Stearns [30] consider curriculum as a factor that build an image for future working. In fact, rural practice needs some skills that are not addressed properly in Iran. At first, medical curriculum in Iran is hospital-oriented; whereas, rural-oriented education increases intention of working in a rural area [14,31]. Though, the students are not getting familiar with skills needed for rural practice. Students' experiences during education is a factor that highly affects retention in rural areas especially during first years of education [32]. Hence, courses about familiarity of medical students with Family Physician Program, and facing with rural patients during education are needed for guarantee their retention in rural settings.

Lack of GPs knowledge about management and leadership is another challenge in medical curriculum. In fact, in rural settings GPs are the head of health team [12] and they are coor- dinator, community leader for health, administrator, health policy analyzer, and fund holding [33]. On the other hand, GPs role in rural and remote areas is more focusing on health rather than curing patients [33]. GPs coordinate health activities and they need to have a good command of management, health and epidemiology subjects. Nevertheless, these issues are not addressed properly in medical curriculum in Iran.

The last challenges that were found in this research were challenges related to education setting and approach. Instructors and education location as well as education approach could have a significant impact on educated GPs' retention. Training background is a factor that affects retention in rural areas [23]. Hospital oriented education of GPs in Iran, does not make GPs ready for rural practice. Education approach shapes the expectations of GPs and if it is turned to rural-oriented education, we could expect more retention [14]. Community based education could improve quality as well as retention of GPs [34]. In fact, it fills the gap between public health and clinical medicine which is a challenge for rural GPs of Iran.

Instructors also are critical for making students interested in rural practice. Instructors who did not work in rural settings are not a good pattern for GPs who are expected to work in rural settings. Supervisors and instructor roles is very important factor on GPs. Studies have revealed that instructors can have either positive [35] or negative [36] impact on staff morale. Another factor is education place that most of medical students in Iran are educated in big cities. Educations in remote areas and small towns or rural settings have a positive impact on choosing rural settings by GPs [19,31,37-39]. Even changing education setting for a semester from big cities to smaller towns could have a significant effect on rural and remote areas retention [40]. Though, reform in education setting and moving to education in small towns could be a good policy for making GPs more interested about practice in rural and underserved areas.

The results of this study gives a good oversight about education challenges that makes GPs less interested for working in rural and underserved areas based on experts and GPs experience and viewpoints. The results could guide educational planners and policy makers to reform GPs' education toward making them interested for rural practice. The present qualitative started a way toward educational factors that could affect GPs retention in rural areas of Islamic Republic of Iran; but more researches are needed to survey the effect of each factor on retention. 


\section{ACKNOWLEDGEMENTS}

This study was part of a PhD thesis supported by Tehran University of Medical Sciences (TUMS); grant no. 9021557002.

\section{CONFLICT OF INTEREST}

The authors have no conflicts of interest associated with the material presented in this paper.

\section{ORCID}

Sajad Delavari http://orcid.org/0000-0002-5539-9026

Mohammad Arab http://orcid.org/0000-0002-5637-287X

Arash Rashidian http://orcid.org/0000-0002-4005-5183

Saharnaz Nedjat http://orcid.org/0000-0002-0966-727X

Rahmatollah Gholipour Souteh https://orcid.org/0000-00019081-1576

\section{REFERENCES}

1. Xiang YX, Xiong JY, Tian MM, Yuan F, Feng ZC. Factors influencing the utilization of postpartum visits among rural women in China. J Huazhong Univ Sci Technolog Med Sci 2014;34(6): 869-874.

2. Shen Y, Yan H, Reija K, Li Q, Xiao S, Gao J, et al. Equity in use of maternal health services in Western Rural China: a survey from Shaanxi province. BMC Health Serv Res 2014;14:155.

3. Ganle JK. Ethnic disparities in utilisation of maternal health care services in Ghana: evidence from the 2007 Ghana Maternal Health Survey. Ethn Health 2016;21(1):85-101.

4. Ganle JK, Parker M, Fitzpatrick R, Otupiri E. A qualitative study of health system barriers to accessibility and utilization of maternal and newborn healthcare services in Ghana after userfee abolition. BMC Pregnancy Childbirth 2014;14:425.

5. Su D, Pratt W, Salinas J, Wong R, Pagán JA. Rural-urban differences in health services utilization in the US-Mexico border region. J Rural Health 2013;29(2):215-223.

6. Earle-Richardson G, Scribani M, Scott E, May J, Jenkins P. A comparison of health, health behavior, and access between farm and nonfarm populations in rural New York state. J Rural Health 2015;31(2):157-164.

7. Kulig JC, Kilpatrick K, Moffitt P, Zimmer L. Recruitment and retention in rural nursing: it's still an issue! Nurs Leadersh (Tor Ont) 2015;28(2):40-50.
8. Rahman FR, Maharaj V, Yates R, Beeley C, Moore I, Rose A, et al. Addressing the inverse care law: the role of community paediatric services. Perspect Public Health 2014;134(2):85-92.

9. Moosa S, Wojczewski S, Hoffmann K, Poppe A, Nkomazana O, Peersman $\mathrm{W}$, et al. The inverse primary care law in sub-Saharan Africa: a qualitative study of the views of migrant health workers. Br J Gen Pract 2014;64(623):e321-e328.

10. McLean G, Guthrie B, Mercer SW, Watt GC. General practice funding underpins the persistence of the inverse care law: cross-sectional study in Scotland. Br J Gen Pract 2015;65(641): e799-e805.

11. Unwin J, Peters D. Gatekeepers and the Gateway--a mixedmethods inquiry into practitioners' referral behaviour to the Gateway Clinic. Acupunct Med 2009;27(1):21-25.

12. Takian A, Doshmangir L, Rashidian A. Implementing family physician programme in rural Iran: exploring the role of an existing primary health care network. Fam Pract 2013;30(5): 551-559.

13. Khayatzadeh-Mahani A, Takian A. Family physician program in Iran: considerations for adapting the policy in urban settings. Arch Iran Med 2014;17(11):776-778.

14. Qing Y, Hu G, Chen Q, Peng H, Li K, Wei J, et al. Factors that influence the choice to work in rural township health centers among 4,669 clinical medical students from five medical universities in Guangxi, China. J Educ Eval Health Prof 2015;12:40.

15. Kawamoto R, Uemoto A, Ninomiya D, Hasegawa Y, Ohtsuka N, Kusunoki T, et al. Characteristics of Japanese medical students associated with their intention for rural practice. Rural Remote Health 2015;15(2):3112.

16. Landy DC, Gorin MA, Egusquiza JD, Weiss J, O'Connell MT. Medical student attitudes before and after participation in rural health fairs. J Res Med Sci 2012;17(3):298-303.

17. Wurie HR, Samai M, Witter S. Retention of health workers in rural Sierra Leone: findings from life histories. Hum Resour Health 2016;14:3.

18. Jones MP, Humphreys JS, Nicholson T. Is personality the missing link in understanding recruitment and retention of rural general practitioners? Aust J Rural Health 2012;20(2):74-79.

19. Walker JH, Dewitt DE, Pallant JF, Cunningham CE. Rural origin plus a rural clinical school placement is a significant predictor of medical students' intentions to practice rurally: a multi-university study. Rural Remote Health 2012;12:1908.

20. Wasko K, Jenkins J, Meili R. Medical practice in rural Saskatchewan: factors in physician recruitment and retention. Can J Rural Med 2014;19(3):93-98. 
21. Sapkota BP, Amatya A. What factors influence the choice of urban or rural location for future practice of Nepalese medical students? A cross-sectional descriptive study. Hum Resour Health 2015;13:84.

22. Zambrano LI, Pereyra-Elías R, Reyes-García SZ, Fuentes I, Mayta-Tristán P. Influence of parental education on Honduran medical students' labour perspectives: rural work and emigration. Can J Rural Med 2015;20(4):121-128.

23. Laurence CO, Eley DS, Walters L, Elliott T, Cloninger CR. Personality characteristics and attributes of international medical graduates in general practice training: Implications for supporting this valued Australian workforce. Aust J Rural Health 2016;24(5):333-339.

24. Myroniuk L, Adamiak P, Bajaj S, Myhre DL. Recruitment and retention of physicians in rural Alberta: the spousal perspective. Rural Remote Health 2016;16(1):3620.

25. Dossajee H, Obonyo N, Ahmed SM. Career preferences of final year medical students at a medical school in Kenya: a cross sectional study. BMC Med Educ 2016;16:5.

26. Amiresmaili M, Khosravi S, Feyzabadi VY. Factors affecting leave out of general practitioners from rural family physician program: a case of Kerman, Iran. Int J Prev Med 2014;5(10): 1314-1323.

27. Wood ME, Mansoor GF, Hashemy P, Namey E, Gohar F, Ayoubi $S F$, et al. Factors influencing the retention of midwives in the public sector in Afghanistan: a qualitative assessment of midwives in eight provinces. Midwifery 2013;29(10):1137-1144.

28. Kruger E, Tennant M. Short-stay rural and remote placements in dental education, an effective model for rural exposure: a review of eight-year experience in Western Australia. Aust J Rural Health 2010;18(4):148-152.

29. Eley D, Baker P. Does recruitment lead to retention? Rural clinical school training experiences and subsequent intern choices. Rural Remote Health 2006;6(1):511.

30. Stearns JA, Stearns MA. Graduate medical education for rural physicians: curriculum and retention. J Rural Health 2000;16 (3):273-277.

31. Lee J, Walus A, Billing R, Hillier LM. The role of distributed education in recruitment and retention of family physicians. Postgrad Med J 2016;92(1090):436-440.
32. Boehm J, Cordier R, Thomas Y, Tanner B, Salata K. The first year experience of occupational therapy students at an Australian regional university: promoting student retention and developing a regional and remote workforce. Aust J Rural Health 2015. doi: https://doi.org/10.1111/ajr.12252.

33. Khosravan S, Karimi Moonaghi H, Yazdani S, Ahmadi S, Mansoorian MR. Leadership and management curriculum planning for Iranian general practitioners. J Adv Med Educ Prof 2015;3(4):159-165.

34. Talib ZM, Baingana RK, Sagay AS, Van Schalkwyk SC, Mehtsun $S$, Kiguli-Malwadde E. Investing in community-based education to improve the quality, quantity, and retention of physicians in three African countries. Educ Health (Abingdon) 2013; 26(2):109-114.

35. Hartley S, Macfarlane F, Gantley M, Murray E. Influence on general practitioners of teaching undergraduates: qualitative study of London general practitioner teachers. BMJ 1999;319 (7218):1168-1171.

36. Sturman N, Régo P, Dick ML. Rewards, costs and challenges: the general practitioner's experience of teaching medical students. Med Educ 2011;45(7):722-730.

37. Wilkinson D, Birks J, Davies L, Margolis S, Baker P. Preliminary evidence from Queensland that rural clinical schools have a positive impact on rural intern choices. Rural Remote Health 2004;4(4):340.

38. Allen SM, Ballweg RA, Cosgrove EM, Engle KA, Robinson LR, Rosenblatt RA, et al. Challenges and opportunities in building a sustainable rural primary care workforce in alignment with the Affordable Care Act: the WWAMI program as a case study. Acad Med 2013;88(12):1862-1869.

39. Pagaiya N, Kongkam L, Sriratana S. Rural retention of doctors graduating from the rural medical education project to increase rural doctors in Thailand: a cohort study. Hum Resour Health 2015;13:10.

40. Winn CS, Chisholm BA, Hummelbrunner JA, Tryssenaar J, Kandler LS. Impact of the Northern Studies Stream and Rehabilitation Studies programs on recruitment and retention to rural and remote practice: 2002-2010. Rural Remote Health 2015; 15(2):3126. 